\title{
Demonstrative Study of Vehicles Using Waste Vegetable Oil as Fuel
}

\author{
Yasuyuki Nemoto ${ }^{1}$ and Izumi Ushiyama ${ }^{2}$ \\ 1. Division of Renewable Energy and Environment, Ashikaga Institute of Technology, Ashikaga-shi 326-8558, Japan \\ 2. Graduate School, Ashikaga Institute of Technology, Ashikaga-shi 326-8558, Japan
}

Received: October 31, 2014 / Accepted: December 02, 2014 / Published: February 28, 2015.

\begin{abstract}
SVO (straight vegetable oil) method means the direct use of vegetable oil as car fuel through installation of a heater unit in the car to decrease vegetable oil viscosity. In this study, the authors carried out performance tests on the direct use of waste cooking oil using a car with a heater unit. Moreover, the authors carried out long run driving on road tests in five years using a public car of Minami-Aizu Town in Fukushima Prefecture and analyzed the case of troubles and clarified the availability and problems of SVO vehicles. As a result, the car with a heater unit shows similar performance in both cases using vegetable oil or diesel fuel as fuel. The tested SVO vehicle of Minami-Aizu Town could be driven 38,127 km mainly by waste vegetable oil with a total driving distance of $52,293 \mathrm{~km}$ in long run driving tests in five years, and decreased about 3,813.5 liters of light oil which corresponds to $9.99 \mathrm{t}$ of $\mathrm{CO}_{2}$.
\end{abstract}

Key words: Waste cooking oil, straight vegetable oil, bio-fuel.

\section{Introduction}

Various kinds of vegetable oil and waste cooking oil are in fact used as car fuel all over the world. In general, "bio-diesel", i.e., fatty acid methyl ester extracted from such oil is utilized as fuel for vehicles. However, bio-diesel has some problems such as treatment of by-products and waste materials created during transesterification.

An alternative method is SVO (straight vegetable oil) method which means the direct use of vegetable oil as car fuel through installation of a heater unit in the car to decrease vegetable oil viscosity. SVO method has the following advantages: (1) auxiliary materials such as methanol and catalysts are not necessary; (2) by-products such as glycerin and waste fluid are not generated; (3) it is not necessary to treat hazardous materials on the fire defense law such as bio-diesel and methano; (4) operators for bio-diesel producer are not required.

Corresponding author: Yasuyuki Nemoto, Ph.D., professor, research fields: energy conversion system using renewable energy. E-mail: nemoto@ashitech.ac.jp.
As for SVO method, some studies were carried out such as study on engine performance and emissions from engines when rape seed oil or waste vegetable oil is used as fuel $[1,2]$. However, the number of studies on SVO is fewer than ones on bio-diesel. Furthermore, there are few studies on long-run driving performance of SVO vehicles.

The authors of this study carried out performance tests on the direct use of waste cooking oil using a car with a heater unit. Moreover, the authors carried out long run driving on road tests in five years using a public car of Minami-Aizu Town in Fukushima Prefecture and analyzed the case of troubles and clarified the availability and problems of SVO vehicles.

\section{Tests on Basic Performance of SVO Vehicle}

\subsection{Tested Car}

First, the authors made a car to test waste cooking oil as fuel by equipping a heater unit, a filter unit, pipes and a sub fuel tank for diesel fuel to a used Toyota Estima Diesel KD-CXR10G. Table 1 shows the specifications of the original car; Fig. 1 shows the 
Table 1 Specification of original car.

\begin{tabular}{ll}
\hline Name & Toyota Estima Lucida \\
\hline Type & KD-CXR10G \\
Production year & 1998 \\
Weight & $1,660 \mathrm{~kg}$ \\
Size & $4,690 \times 1,690 \times 1,790 \mathrm{~mm}$ \\
Capacity & eight persons \\
Type of engine & 3C-TE (in line four cylinders OHC \\
Bore $\times$ Stroke & IC turbo diesel engine) \\
Displacement & $86.0 \mathrm{~mm} \times 94.0 \mathrm{~mm}$ \\
Compression rate & $2,184 \mathrm{cc}$ \\
Fuel supply system & EFI $(\mathrm{electric}$ fuel injection $)$ \\
Maximum power & $105 \mathrm{ps}(77 \mathrm{~kW}) / 4,200 \mathrm{rpm}$ \\
Maximum torque & $23.0 \mathrm{~kg} \cdot \mathrm{m}(225.6 \mathrm{~N} \cdot \mathrm{m}) / 2,600 \mathrm{rpm}$ \\
Transmission & $4 \mathrm{AT}$ \\
\hline
\end{tabular}

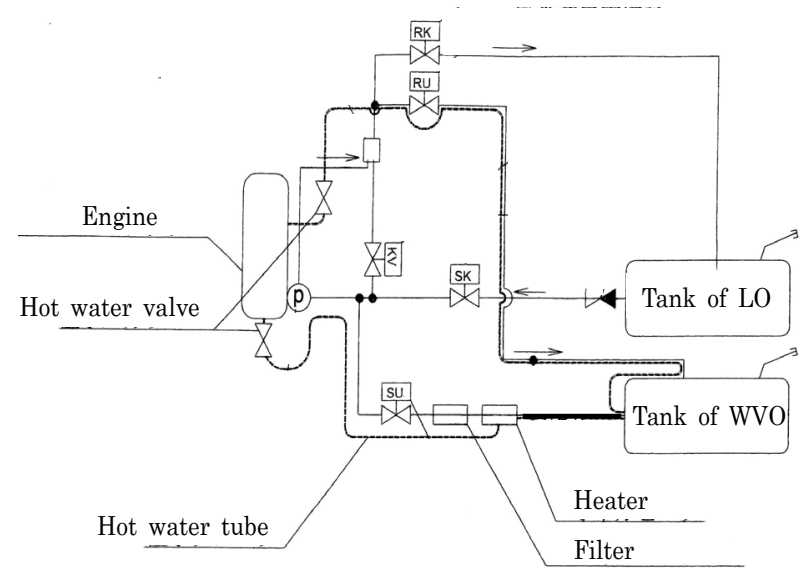

Fig. 1 Systematic diagram of SVO vehicle.

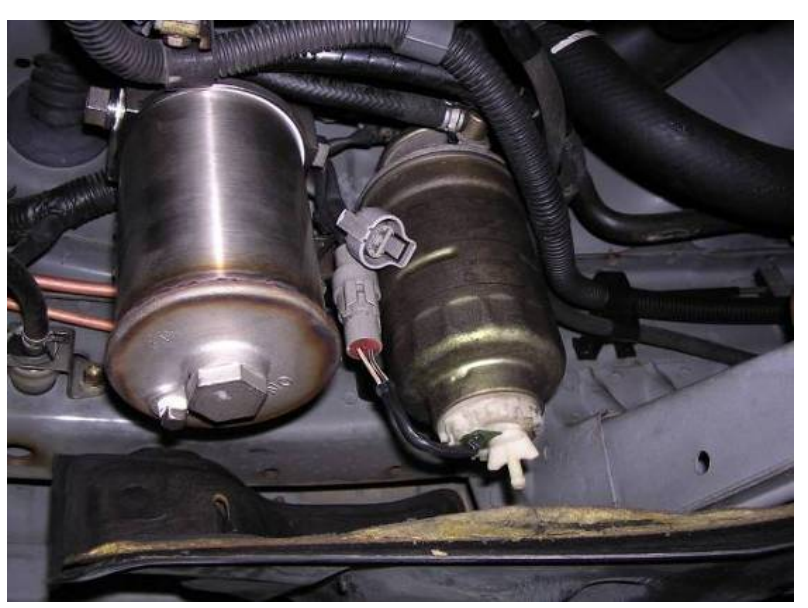

Fig. 2 Heater and filter of the direct-use-system.

systematic diagram of the direct-use system; Fig. 2 shows the picture of a heater unit and a filter unit. Vegetable oil is heated and decreased the viscosity by heat exchange with hot water from the car radiator in the heater. Mesh of the filter element is five micron.

The tested car has a main fuel tank for vegetable oil and a sub fuel tank for diesel fuel. The newly established filler is only different from a general car in the appearance. Two completely different pipes are used from two tanks to the engine to avoid the mixture. The tested car has a switch to change the mode between diesel fuel, vegetable oil and automatic. At automatic mode, diesel fuel is used as fuel at engine starting, vegetable oil is used at more than $40{ }^{\circ} \mathrm{C}$ of hot water from car radiator and diesel fuel is circulated after stopping the engine. This car has acquired the car certificate from the transportation bureau, so can be driven on public roads.

\subsection{Results of Chassis Dynamo Tests}

The authors carried out performance tests of a car with direct-use-system by chassis dynamo-D-6000S of Sakura Dyno System Corporation. Diesel fuel and waste cooking oil were used as fuel for comparison. Waste vegetable oil used for the tests was filtered by 0.5 micron mesh before refueling. Table 2 shows the characteristics of diesel fuel and waste vegetable oil that were used for the tests.

Fig. 3 shows the results of the chassis dynamo tests. The maximum power was $105.5 \mathrm{ps} / 3,700 \mathrm{rpm}$ at waste vegetable oil and $107.4 \mathrm{ps} / 3,800 \mathrm{rpm}$ at diesel fuel. The car showed similar performance in both cases using either waste vegetable oil or diesel fuel as fuel [3].

Table 2 Characteristics of each fuel.

\begin{tabular}{|c|c|c|c|}
\hline & Light oil & $\begin{array}{l}\text { Waste } \\
\text { vegetable } \\
\text { oil }\end{array}$ & $\begin{array}{l}\text { Testing } \\
\text { method }\end{array}$ \\
\hline Specific gravity (-) & 0.8247 & 0.9236 & JIS K-2249 \\
\hline $\begin{array}{l}\text { Lower heating value } \\
(\mathrm{MJ} / \mathrm{kg})\end{array}$ & 45.58 & 39.67 & JIS K-2279 \\
\hline $\begin{array}{l}\text { Lower heating value } \\
(\mathrm{MJ} / \mathrm{L})\end{array}$ & 37.59 & 36.64 & (reference) \\
\hline $\begin{array}{l}\text { Kinetic viscosity } \\
\left(\mathrm{mm}^{2} / \mathrm{s}\right)\end{array}$ & $\begin{array}{l}3.224 \\
\left(30^{\circ} \mathrm{C}\right)\end{array}$ & $\begin{array}{l}57.05 \\
\left(30^{\circ} \mathrm{C}\right)\end{array}$ & JIS K-2283 \\
\hline $\begin{array}{l}\text { Total sulfur content } \\
(\mathrm{wt} \%)\end{array}$ & $<0.01$ & $<0.01$ & JIS K-2541 \\
\hline Acid value (mg-KOH/g) & - & 1.52 & $\begin{array}{l}\text { Standard of } \\
\text { JOCS }\end{array}$ \\
\hline Iodine value $\left(\mathrm{g}-\mathrm{I}_{2} / 100 \mathrm{~g}\right)$ & - & 128 & WIJS method \\
\hline
\end{tabular}



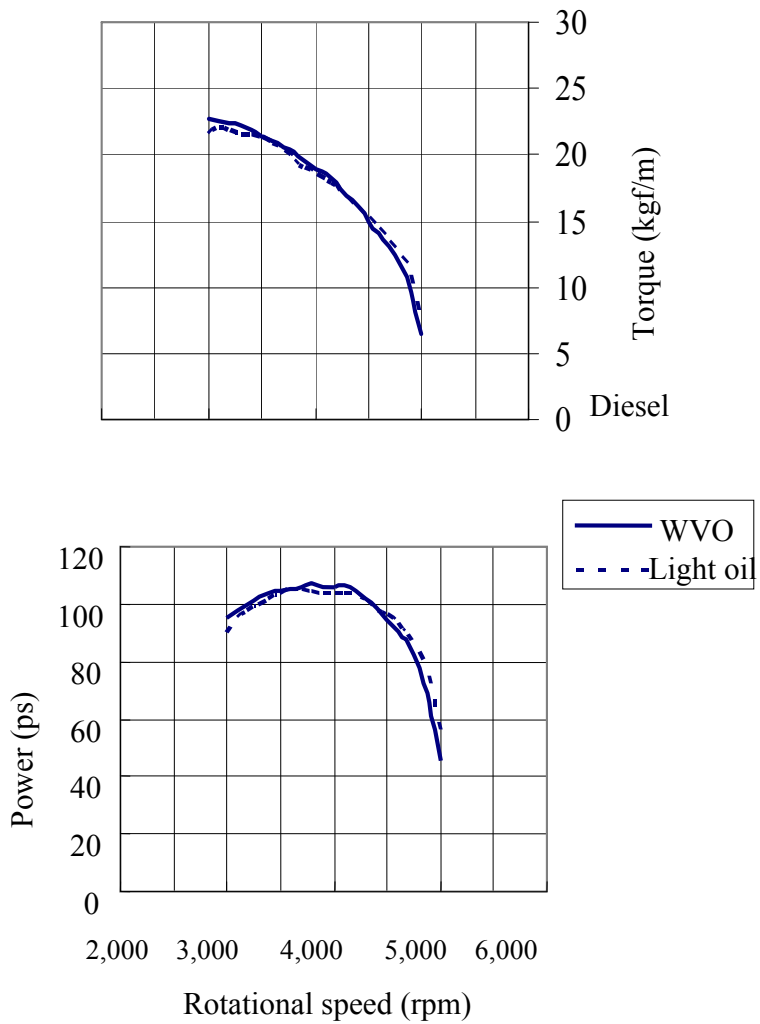

Fig. 3 Results of chassis dynamo tests.

\subsection{Results of On-road Tests}

The authors have continuously carried out on road tests of the car with direct-use-system of waste vegetable oil. The data of place, altitude, velocity and acceleration of the car are sampled at every second and all recorded by GPS system installed in the car since August, 2007.

Fig. 4 shows an example of the results of on road tests. These data were obtained by driving $300 \mathrm{~km}$ of roads including highway and mountain roads on October 17, 2007. The car could be driven on roads with $800 \mathrm{~m}$ of altitude difference shown in Fig. $5 \mathrm{a}$ and on high-way by more than $100 \mathrm{~km} / \mathrm{h}$ stably shown in Fig. 5b. Although this car uses diesel fuel only at cold-starting and after stopping the engine, about $95 \%$ of consumed fuel was waste vegetable oil on this day.

Fig. 5 shows the results of the on-road tests during the winter season. The car could be driven even at $-2{ }^{\circ} \mathrm{C}$ without any problems.

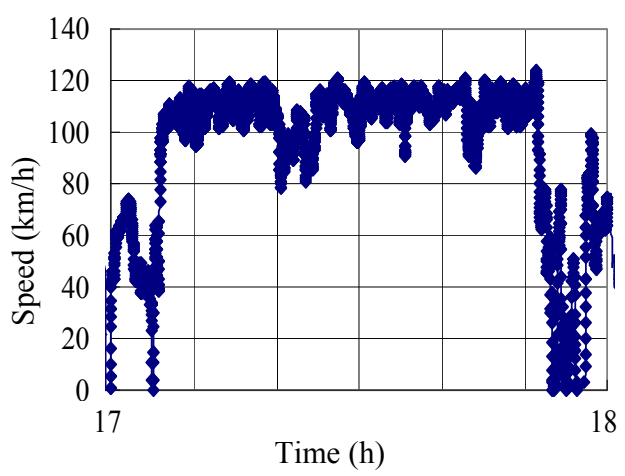

(a) Speed-time

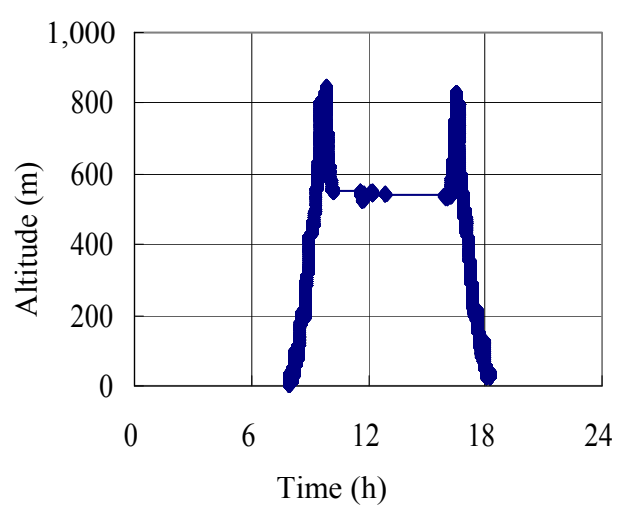

(b) Altitude-time

Fig. 4 Results of on-road tests (1: speed and altitude).

\section{Long-Run Driving Tests in Minami-Aizu Town}

\subsection{Tested Car}

Next, the authors carried out long-run driving tests of the SVO vehicle. The tested SVO vehicle is an official car, which is equipped with a SVO unit, of the Minami-Aizu Town in Fukushima Prefecture. Its original car was a Mitsubishi Pajero Diesel $\mathrm{KC}-\mathrm{V} 46 \mathrm{~V}$, which was produced in 1998 and its displacement is $2,835 \mathrm{cc}$. Fig. 6 shows its picture. This car has also acquired the car certificate from the transportation bureau, so can be driven on public road.

The on-road tests were started from December, 2008 and continue until now. In this period, the authors recorded its driving distance, fuel consumption and number of troubles with data on position, altitude, 
velocity and acceleration by using GPS device. In this paper, the author shows the results in five years from January, 2009.

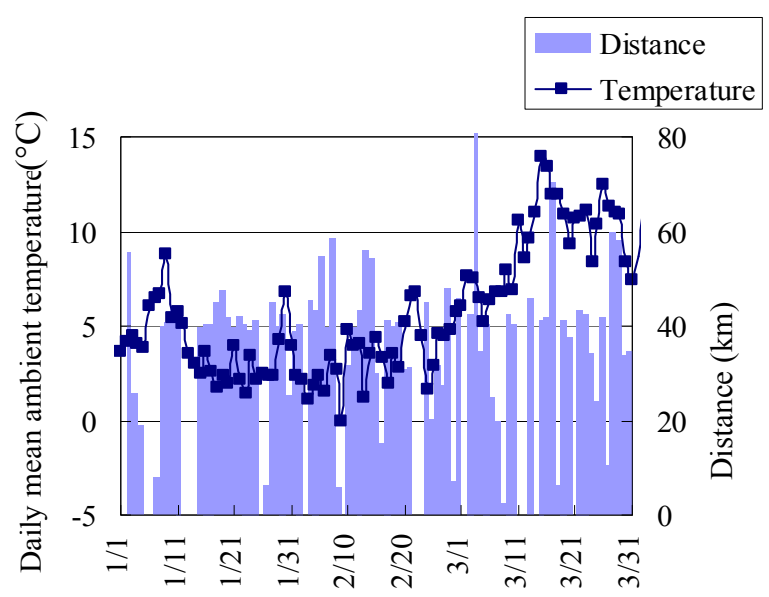

(a) Full data of three months

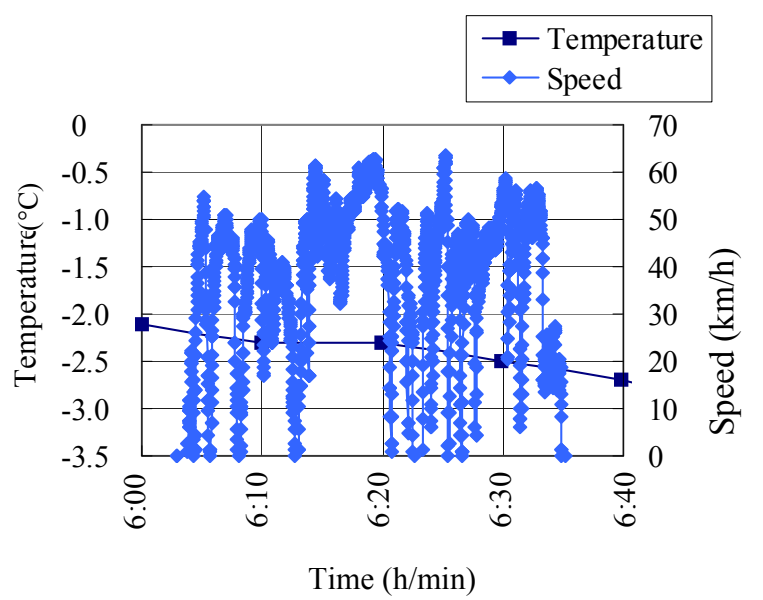

(b) Data on Feb. 5, 2008

Fig. 5 Results of on-road tests (Winter season).

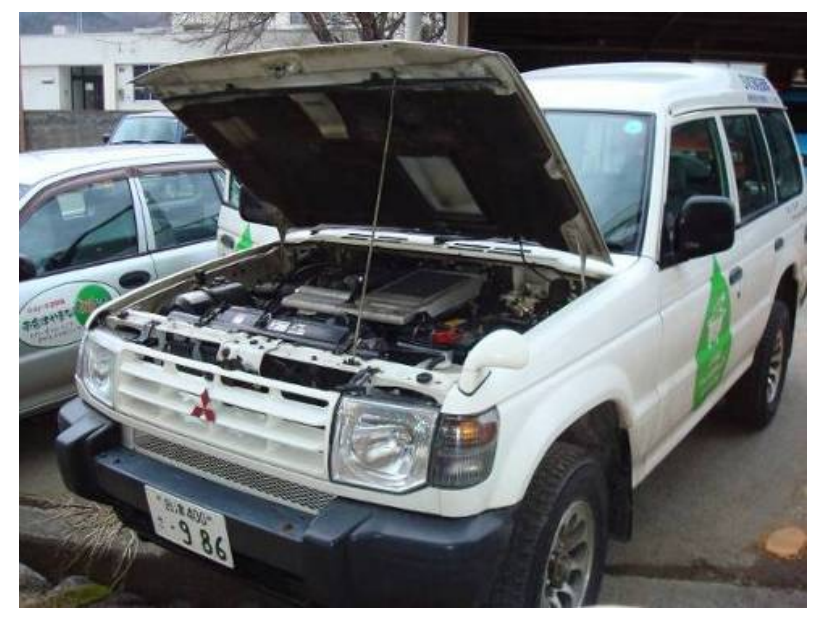

Fig. 6 Public SVO vehicle in Minami-Aizu Town.

\subsection{Results of the Driving Distance and Fuel Consumption}

Fig. 7 shows average, highest and lowest temperature of Minami-Aizu Town in five years from 2009. It is found that the lowest temperature in this town is less than $0{ }^{\circ} \mathrm{C}$.

Figs. 8 and 9 show the driving distance and the fuel consumption of each driving mode of the SVO vehicle. Total distance of each mode was $13,395 \mathrm{~km}, 24,732$ $\mathrm{km}, 14,166 \mathrm{~km}$ in the automatic mode, waste vegetable oil mode, and diesel fuel mode, respectively.

It is also found that the automatic mode is mainly used from January to April, and on the other hand, the waste vegetable oil mode was mainly used from May to September. It is thought that the reason is the users of SVO vehicle who had used the automatic mode first understood that the waste vegetable mode is convenient under warm temperature condition.

On the other hand, it is found that the diesel fuel mode was highly used from October to December. From these results, it is guessed that some problems occur in the use of waste vegetable oil mode under cold conditions from October.

Fig. 10 shows the relation between the total mirage of each driving mode and the temperature. It is found that usage of waste vegetable oil increases on the day at higher than about $10^{\circ} \mathrm{C}$ of lowest temperature. On the other hand, diesel fuel was mainly used at lower than $5{ }^{\circ} \mathrm{C}$. This means the drivers selected diesel fuel

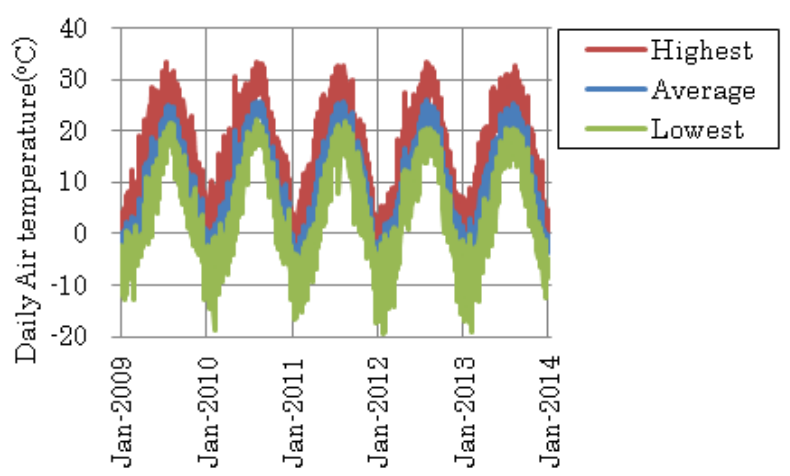

Fig. 7 Temperature in the period of on-road test. 


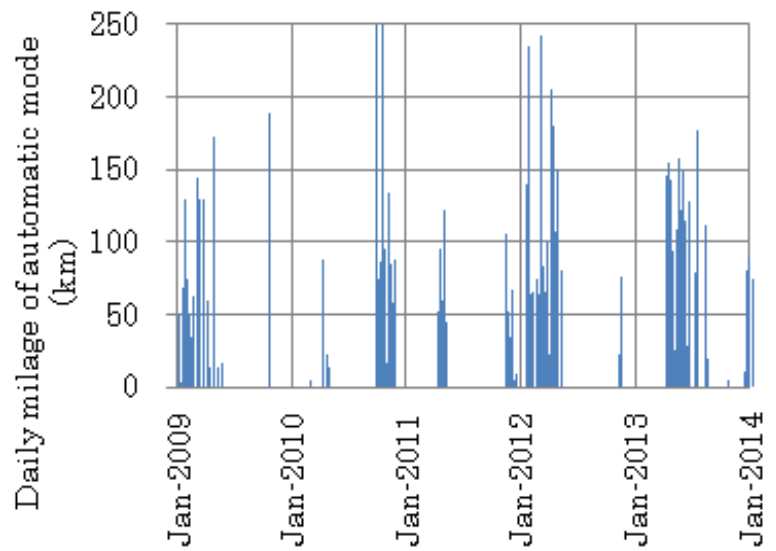

(a) Automatic mode

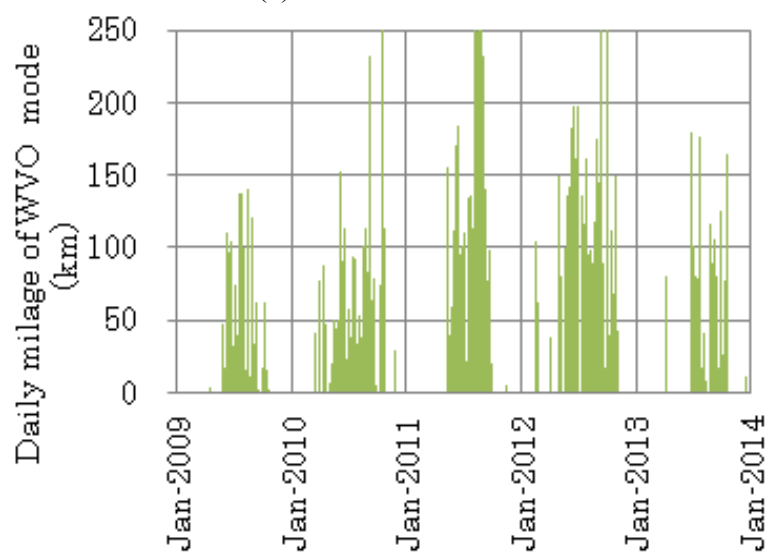

(b) Waste vegetable mode

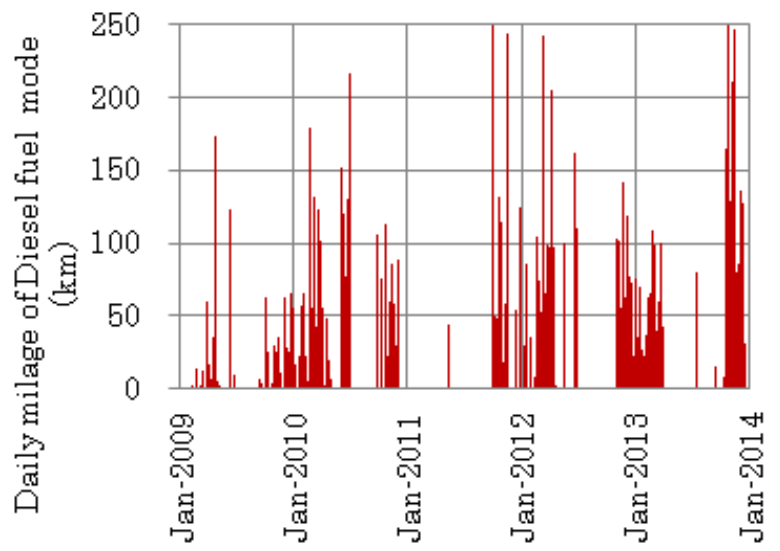

(c) Diesel fuel mode

Fig. 8 Driving-mode of tested car.

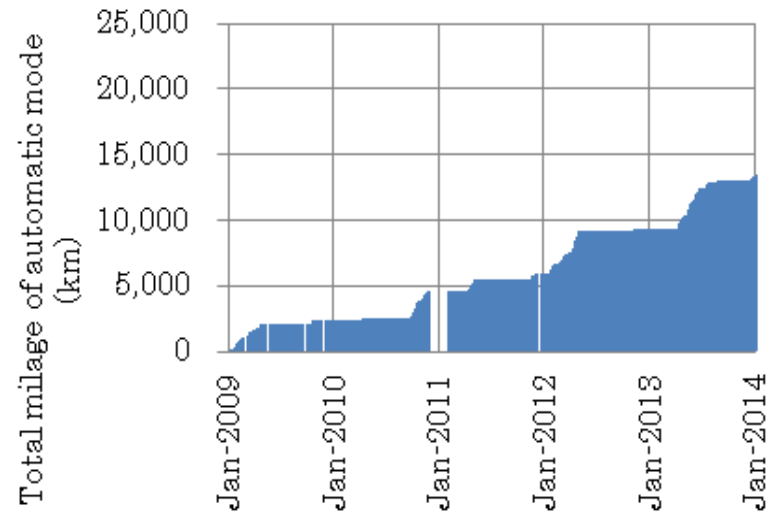

(a) Automatic mode

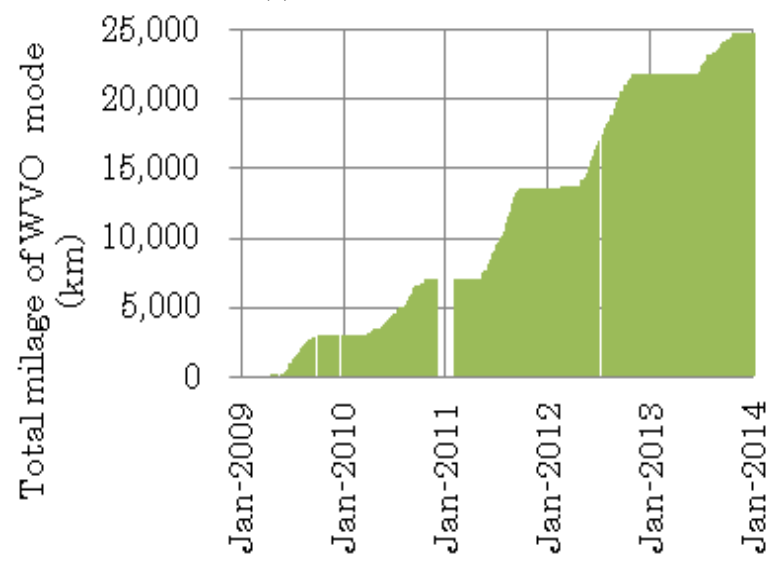

(b) Waste vegetable oil mode

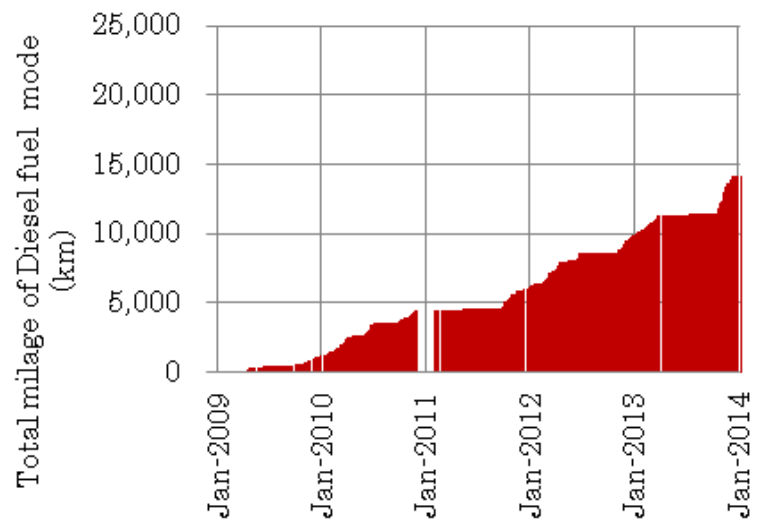

(c) Diesel fuel mode

Fig. 9 Driving-mode of tested car (accumulated). 


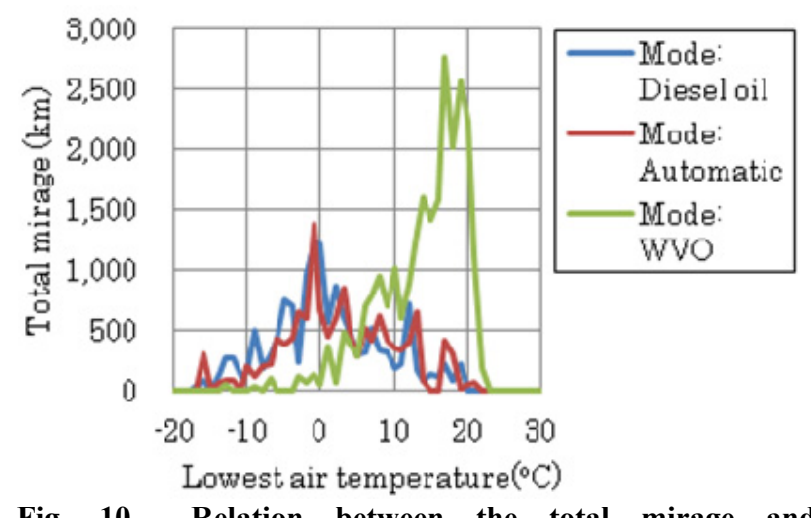

Fig. 10 Relation between the total mirage and temperature.

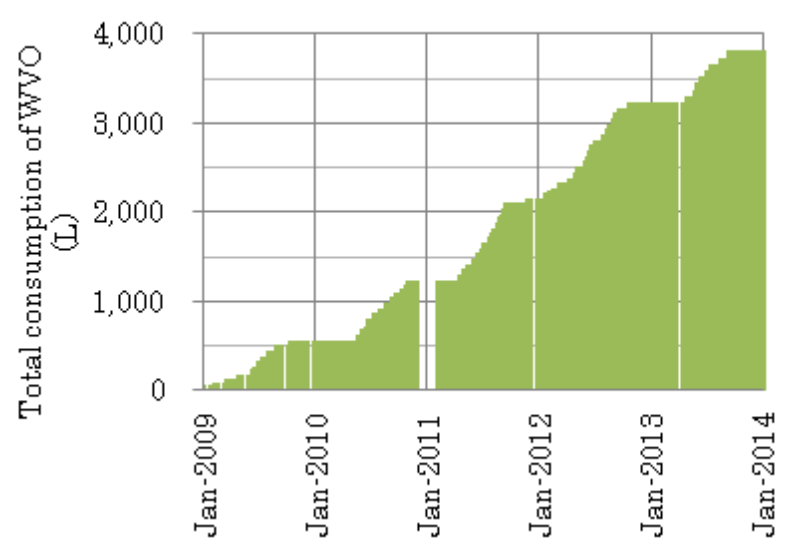

(a) Waste vegetable oil

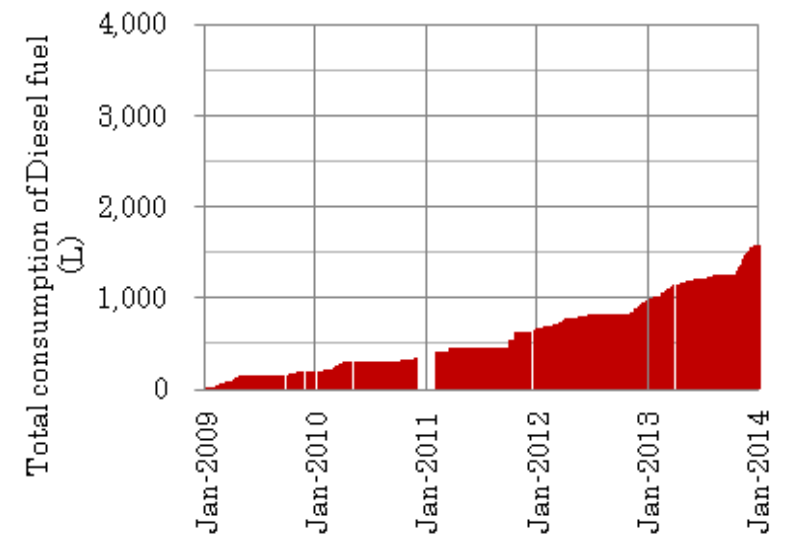

(b) Diesel fuel

Fig. 11 Fuel consumption of tested car (accumulated).

mode or automatic for avoiding the troubles. In other words, the occurrence of troubles remarkably decreases at higher temperature.

Fig. 11 shows the consumption of waste vegetable oil and diesel fuel. Total consumption of waste vegetable oil and diesel fuel was 3,813.5 liters and
1,580.6 liters, respectively. As the $\mathrm{CO}_{2}$ emission rate of light oil is $2.6192 \mathrm{~kg}-\mathrm{CO}_{2} /$ liter, this corresponds to a $\mathrm{CO}_{2}$ reduction of $9.99 \mathrm{t}$ in five years.

\subsection{Analysis of Trouble Cases}

Table 3 shows the number of troubles caused in the SVO vehicle of Minami-Aizu Town in five years from 2009. It is found that trouble with starting the engine was the most common, and instability of idling, trouble of parts and engine stopping followed.

Table 4 shows the list of the replaced parts in five years. Battery, fuel hose, fuel filter, glow lamp, injection pump are included. The number of the occurrence gradually decreases according to passage of the time after start of the use. Most of recent replaced parts are usually necessary for general cars.

Table 3 Classifications of troubles in the period of on-road test.

\begin{tabular}{ll}
\hline Case & Times \\
\hline Trouble at starting engine & 21 \\
Instability of idling & 16 \\
Engine stopping & 9 \\
\hline
\end{tabular}

Table 4 List of replaced parts.

\begin{tabular}{|c|c|c|c|}
\hline Date & Replacement parts & Date & $\begin{array}{l}\text { Replacement } \\
\text { parts }\end{array}$ \\
\hline \multirow[b]{2}{*}{$2009 / 3 / 9$} & Battery & \multirow[b]{2}{*}{$2010 / 7 / 31$} & Engine oil \\
\hline & Fuel hose and band & & $\begin{array}{l}\text { Oil pressure } \\
\text { switch }\end{array}$ \\
\hline \multirow{2}{*}{ 2009/3/19 } & Fuel filter & \multirow{2}{*}{$2010 / 11 / 29$} & Engine oil \\
\hline & Glow lamp & & Element oil \\
\hline & Bracket & $2012 / 1 / 13$ & Glow plug \\
\hline \multirow{3}{*}{$2009 / 5 / 1$} & Coolant & $2012 / 3 / 9$ & Fusible link \\
\hline & solenoid valve & $2012 / 6 / 8$ & Switch \\
\hline & Packing & \multirow{4}{*}{$2012 / 8 / 8$} & Coolant \\
\hline $2009 / 5 / 8$ & Injection pump & & Pulley \\
\hline \multirow{2}{*}{$2009 / 12 / 7$} & Glow plug & & $\begin{array}{l}\text { Crank angle } \\
\text { blade }\end{array}$ \\
\hline & Water temp. sensor & & $\begin{array}{l}\text { Crank angle } \\
\text { sensor }\end{array}$ \\
\hline $2010 / 2 / 25$ & \multirow{2}{*}{$\begin{array}{l}\text { Fuel filter } \\
\text { Gas for air } \\
\text { conditioner }\end{array}$} & & Bolts \\
\hline $2010 / 6 / 21$ & & $2012 / 11 / 30$ & Fuel filter \\
\hline \multirow{4}{*}{$2010 / 6 / 30$} & Engine oil & & WVO filter \\
\hline & WVO filter & $2013 / 1 / 28$ & Car mirror \\
\hline & Element oil & $2013 / 4 / 24$ & Engine oil \\
\hline & Fuel filter & $2013 / 5 / 1$ & Electric code \\
\hline
\end{tabular}




\section{Conclusion}

The authors carried out performance tests and long run driving tests on the direct use of waste vegetable oil using a car with a heater unit.

As a result, the following conclusions were deduced:

(1) Tested SVO vehicle could be driven $38,053 \mathrm{~km}$ mainly by WVO with a total driving distance of $52,219 \mathrm{~km}$ in long run driving tests in five year;

(2) 3,813.5 liters $(70.7 \%)$ of waste vegetable oil and $1,580.8$ liters $(29.3 \%)$ were used in long run driving tests in five years. This corresponds to a $\mathrm{CO}_{2}$ reduction of $9.99 \mathrm{t}$;

(3) Less than about $10{ }^{\circ} \mathrm{C}$ of the lowest air temperature, some counter plans for coldness are necessary for using SVO system;

(4) On the other hand, no big problem was caused under the condition of more than about $10{ }^{\circ} \mathrm{C}$ of the lowest air temperature. So, there is a possibility to apply the SVO system to warm weather countries such as South Asia and Africa. Also, there is a possibility to apply the SVO system to engine generation systems which is used in the warm building's room, even in cold weather countries.

\section{Acknowledgements}

The authors also acknowledge the support of
Minami-Aizu Town in Fukushima Prefecture and Hokkaido Olympia Corporation.

\section{Reference}

[1] Worldwatch Institute. 2006. Biofuels for Transpor. 258-9. Earthscan.

[2] Agarwal, D., Kumarb, L., and Agarwal, A. K. 2008. "Performance Evaluation of a Vegetable Oil Fuelled Compression Ignition Engine.” Renewable Energy 33 (6): 1147-56.

[3] Morimune, T., Yamaguchi, H., and Konishi, K. 2000. "Exhaust Emissiosn and Performance of Diesel Engine Operating on Waste Food-Oil." Trans. Japan Society of Mechanical Engineering (B) 66 (641): 294-99.

[4] Tanaka, J., Korematsu, K., and Nishi, K. 2007. "Study on Diesel Engine Operated by Neat Rapeseed Oil." Journal of the Japan Institute of Energy 86 (5): 332-8.

[5] Nemoto, Y., and Ushiyama, I. 2008. "Demonstration Study on Direct Use of Waste Vegetable Oil as Car Fuel." In Proceedings of the 10th World Renewable Energy Congress: 269-73.

[6] Nemoto, Y., Chen, M., and Ushiyama, I. 2008. "Demonstration Study on Cars with Straight Vegetable Oil systems." Taiyo-Enerugi 34 (6): 73-9. (In Japanese)

[7] Nemoto, Y., Chen, M., and Ushiyama, I. 2010. "Demonstration Study on Straight Vegetable Oil as Car Fuel." In Proceedings of the Rgnewable Energy 2010, 1-5.

[8] Nemoto, Y., and Ushiyama, I. 2014. "Long Run Tests of Vehicles Using Straight Vegetable Oil as Fuel by a Official Car of a Town." In Proceedings of the Grand Rgnewable Energy 2014, 2-3. 